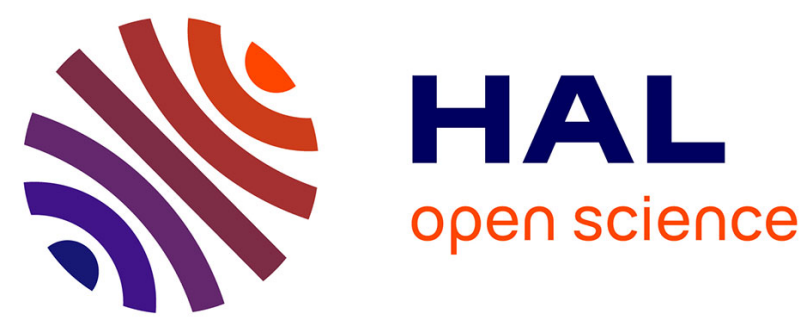

\title{
New Process for Electrical Contacts on (100) N-type Diamond
}

\author{
Nephi Temahuki, Rémi Gillet, Vincent Sallet, François Jomard, \\ Marie-Amandine Pinault-Thaury, Julien Barjon
}

\section{- To cite this version:}

Nephi Temahuki, Rémi Gillet, Vincent Sallet, François Jomard, Marie-Amandine Pinault-Thaury, et al. New Process for Electrical Contacts on (100) N-type Diamond. physica status solidi (a), 2017, 214 (11), pp.1700466. 10.1002/pssa.201700466 . hal-02441414

\section{HAL Id: hal-02441414 \\ https://hal.science/hal-02441414}

Submitted on 10 Dec 2020

HAL is a multi-disciplinary open access archive for the deposit and dissemination of scientific research documents, whether they are published or not. The documents may come from teaching and research institutions in France or abroad, or from public or private research centers.
L'archive ouverte pluridisciplinaire HAL, est destinée au dépôt et à la diffusion de documents scientifiques de niveau recherche, publiés ou non, émanant des établissements d'enseignement et de recherche français ou étrangers, des laboratoires publics ou privés. 


\title{
New process for electrical contacts on (100) n-type diamond
}

\author{
Nephi Temahuki, Rémi Gillet, Vincent Sallet, François Jomard, Marie-Amandine Pinault-Thaury ${ }^{1}$, and \\ Julien Barjon²
}

Groupe d'Etude de la Matière Condensée (GEMaC), CNRS, Université de Versailles St-Quentin-en-Yvelines (UVSQ), Université
Paris Saclay, 45 avenue des Etats-Unis, 78035 Versailles cedex, France

Received ZZZ, revised ZZZ, accepted ZZZ

Published online ZZZ (Dates will be provided by the publisher.)

Keywords phosphorus-doped diamond, electrical contacts, selective microstructuration, nickel etching, MPCVD growth

\begin{abstract}
Obtaining ohmic contacts on n-type diamond is a very compelling concern in the framework of designing power electronic devices. The present contribution considers a new technological process combining microstructuration and highly phosphorus-doped overgrowth to investigate quasi-ohmic contacts on (100) phosphorus doped diamond. For now, the two processes were tested on (100) and (111) diamond single crystal substrates. The results are exposed and discussed.
\end{abstract}

1 Introduction As a semi-conductor, diamond is an interesting material to use for next generation power electronics, ultraviolet light emitting diodes as well as electron emitters $[1,2]$. Since the first demonstration of fabricating n-type diamond with phosphorus as a donor [3], continuous progress has been made toward improving the substitutional dopant incorporation, as well as the global electrical performances of this material. While high conductivities are starting to become suitable for the (111) orientation of phosphorus-doped diamond, being as high as $\sim 10^{-2} \Omega^{-1} . \mathrm{cm}^{-1}$, for doping levels of $\sim 10^{20}$ at. $\mathrm{cm}^{-3}[4]$, the fabrication of (111) oriented diamond devices is limited by the substrate cost, the size and the difficulty of polishing on this orientation. These setbacks do not apply to (100) oriented diamond, which so appears more suited for large scale applications, even when the substitutional phosphorus doping and the electrical conductivity on this orientation both fall behind those of the (111) orientation.

A critical aspect of fabricating phosphorus doped n-type diamond based devices is the contact resistivity of the metal/n-

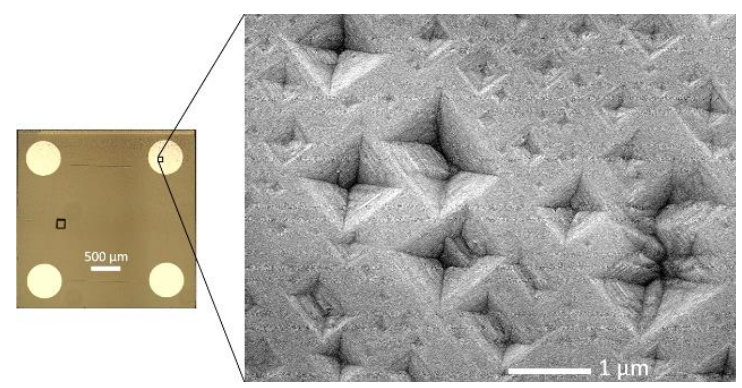

Copyright line will be provided by the publisher

type diamond junction. At this junction, a high Schottky barrier for the electrons is observed whatever be the metal used [5]. It significantly increases the series resistance of any possible n-type diamond-based device. This particular problem can be solved by using an over-doped layer that reduces the spatial extension of the Schottky barrier, allowing the electrons to flow through the junction by tunnel effect. Teraji et al. $[5,6]$ have demonstrated the possibility of creating a selectively overgrown highly phosphorus doped diamond epilayer on top of (111) lightly phosphorus-doped layers by using a mask for the selective overgrowth. This way, they achieved quasi-ohmic contacts. Later on, Kato et al. [7] adapted this principle to the (100) orientation of diamond by using a microstructuration process based on trenches aligned along the [110] direction using lithography and digged with an inductively coupled plasma (ICP) etching method. They were able to selectively overgrow highlyphosphorus doped diamond on (100) in the (111) growth sectors developing from the bottom corners of those

${ }^{1}$ marie-amandine.pinault-thaury@uvsq.fr

2 julien.barjon@uvsq.fr 
trenches, to obtain quasi-ohmic contacts with a low specific contact resistivity.

Another kind of microstructuration is possible to locally obtain (111) oriented surfaces on the main (100) diamond orientation. Smirnov et al. [8] and Mehedi et al. [9] have shown that the deposition of a thin nickel film followed by annealing at about $900^{\circ} \mathrm{C}$ in a hydrogen atmosphere caused the dewetting of the nickel layer into nickel particles, and the catalytic etching of diamond until the formation of inversed pyramidal shaped holes.

In the present work, we investigate the Ni-catalyzed microstructuration of (100) oriented diamond. In parallel, we have determined a set of growth parameters giving high-phosphorus incorporation and high conductivity on (111) surfaces. Finally, we combined these techniques to selectively grow highly-phosphorus doped diamond inside the inverse pyramids of a (100) micro-structured diamond surface.

\section{Experimental}

2.1 Nickel deposition and hydrogen plasma etching on the (100) diamond surface Type Ib HPHT monocrystalline $3 \times 3 \times 1.5 \mathrm{~mm}^{3}$ (100) diamond substrates were purchased from Sumitomo. A nickel layer was deposited on the top half of a substrate, namely Ni-2 (Fig. 1), by using an Edwards Auto 306 vacuum thermal evaporator, with a thickness range between 10 and $45 \mathrm{~nm}$.

This sample was then exposed to a hydrogen plasma during 30 minutes in a Plassys BJS150 micro-wave plasmaassisted chemical vapour deposition (MPCVD) reactor with the following parameters for the temperature, pressure, microwave power and hydrogen flow: $960^{\circ} \mathrm{C}, 125 \mathrm{mbar}, 3000$ $\mathrm{W}$ and $100 \mathrm{sccm}$. This resulted in the etching of diamond by Ni particles as shown in SEM image of Fig.2.a. The nickel particles were subsequently removed from the microstructures by chemical etching in a solution of $70 \%$ nitric acid during 30 minutes at $200^{\circ} \mathrm{C}$, as shown in Fig.2.b.

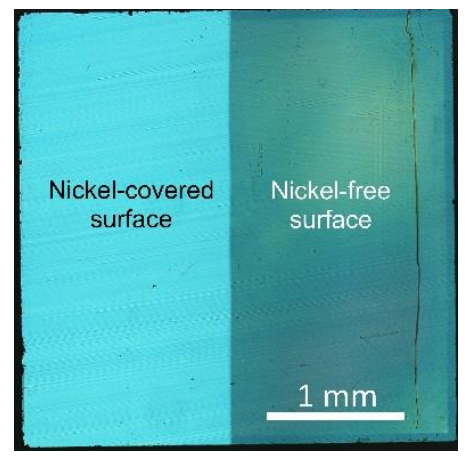

Figure 1 Optical microscopy with a Nomarski filter of sample Ni2 after nickel deposition. The nickel layer was deposited on the left side of the sample.

\section{(a) After hydrogen plasma}

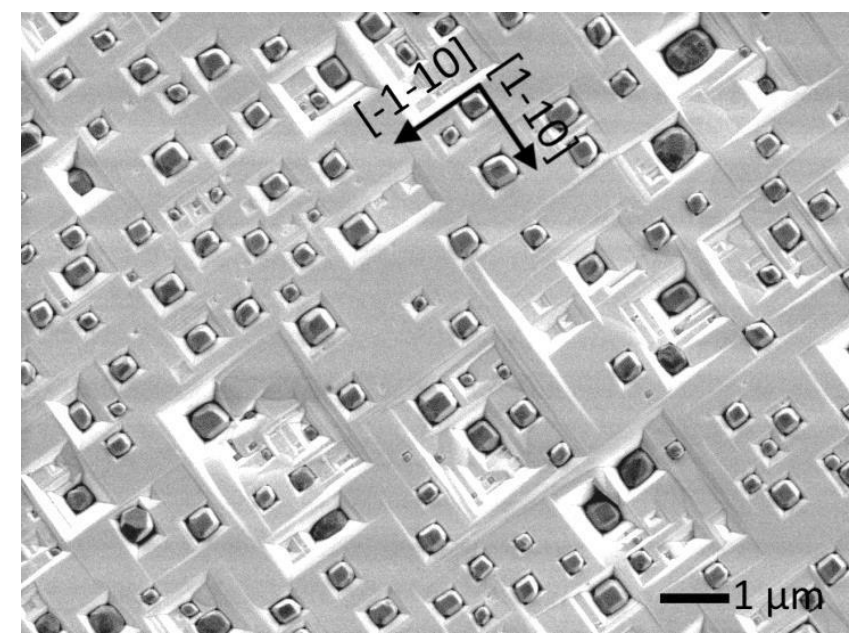

(b) After chemical etching

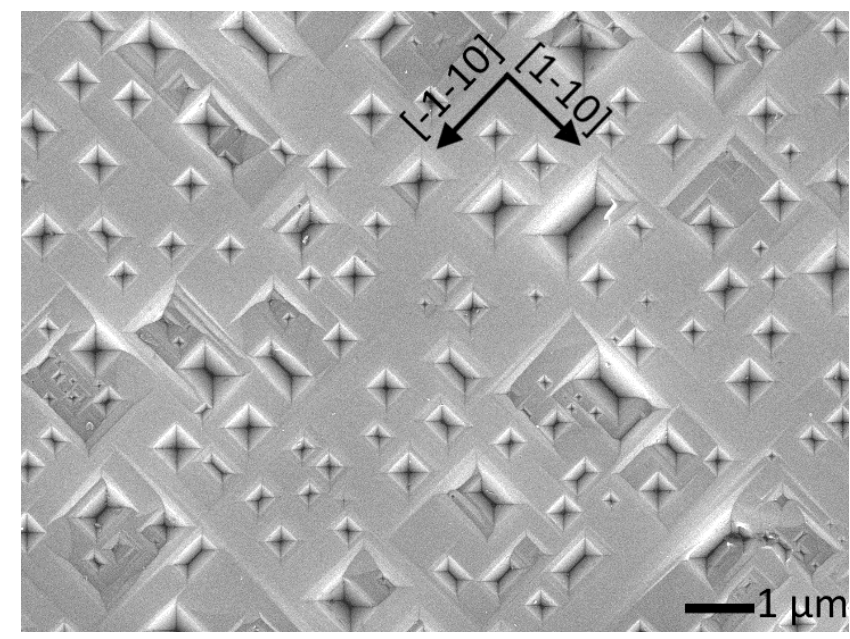

Figure 2 SEM images of the Ni-covered part of sample Ni-2 (a) after $30 \mathrm{~min}$ of hydrogen plasma exposure $\left(960^{\circ} \mathrm{C}, 125 \mathrm{mbar}, 3000\right.$ $\mathrm{W}$ and $100 \mathrm{sccm} \mathrm{H}_{2}$ flow) and (b) after 30 minutes of chemical etching (30 min in $70 \%$ nitric acid at $200^{\circ} \mathrm{C}$ ).

2.2 Growth and overdoping on the (111) orientation of diamond In order to obtain a highly conductive layers on the (111) facets of pyramidal holes, we have first investigated homoepitaxial epilayers grown on the full surface of type Ib HPHT monocrystalline $2 \times 2 \times 0.5 \mathrm{~mm}^{3}(111)$ substrates, also purchased from Sumitomo. The substrates present dispersed values of miscut angle: between $1.6^{\circ}$ and $3.3^{\circ}$. The growth was performed in a home-made MPCVD reactor described elsewhere [10], used for the growth on the (100) orientation with tertiarybutyl-phosphine (TBP) as a dopant source. The incorporation ratio of phosphorus being much lower on (100) than on (111) surfaces, the phosphorus doping on (100) requires high amounts of TBP [11] which induces a high residual content of phosphorus in layers 
grown on the (111)-orientation. This contamination problem is the reason why the phosphorus doping of diamond usually requires two growth reactors: one dedicated to low TBP pressure, suited to the (111) orientation, and another one dedicated to high TBP pressures, suited to the (100) orientation.

In this work, no intentional TBP was introduced in the gas mixture during the (111) growth. The conditions used for n-type (111) homoepitaxy were the following: total gas flow of $1000 \mathrm{sccm}$, with $\left[\mathrm{CH}_{4}\right] /\left[\mathrm{H}_{2}\right]=0.05 \%$ and a pressure of 50 mbar. The growth temperatures, $\mathrm{T}_{\text {growth }}$, and growth durations are reported in Table 1. With this approach, the different $\mathrm{T}_{\text {growth }}$ and growth durations investigated gives phosphorus concentrations in the range of $1-2 \times 10^{20} \mathrm{at} / \mathrm{cm}^{3}$, which is known as the maximum incorporation achievable on the (111) orientation $[4,7,12]$. It indicates that the contamination of the reactor chamber after a (100) growth is sufficient to reach the "solubility" limit of phosphorus on the (111) orientation. This ensures the reproducibility of phosphorus incorporation on the (111) facets of etched pyramidal holes. This choice further avoids the use of two different growth reactors for (100) and (111) diamond surfaces.

2.3 Characterization The surface of sample Ni-2 was observed by using a differential interference microscope with a Nomarski filter and secondary electron microscopy (SEM) with a JEOL 7001F. Atomic Force Microscopy measurements were performed using a Bruker AXS Dimension 3100 in tapping mode with a Bruker RTESP-300 antimony-doped silicon probe with a resistivity range of 0.010 $0.025 \Omega$.cm, a resonance frequency of $300 \mathrm{kHz}$ and a spring constant of $40 \mathrm{~N} / \mathrm{m}$.

Secondary ion mass spectrometry (SIMS) has been performed in order to measure the absolute phosphorus concentration $[\mathrm{P}]$ and the thickness of the epilayers. For the measurements, we have used CAMECA IMS equipments: an IMS4f for samples grown during more than $1 \mathrm{~h}$ and an IMS7f for samples grown during $1 \mathrm{~h}$. $\mathrm{A} \mathrm{Cs}^{+}$ion beam was used as the primary beam with an energy of $10 \mathrm{keV}$ and a current of $80 \mathrm{nA}$ (IMS4f) and $20 \mathrm{nA}$ (IMS7f). Secondary ions were detected in the negative mode leading to $14.5 \mathrm{keV}$ (IMS4f) and $15 \mathrm{keV}$ (IMS7f) of interaction energy of the primary $\mathrm{Cs}^{+}$ions and to $27^{\circ}$ (IMS4f) and $23.6^{\circ}$ (IMS7f) of incidence angle with respect to the normal of the sample. The sputtering rate was around $4 \AA / \mathrm{s}$ and $1.35 \AA / \mathrm{s}$ for the IMS4f and IMS7f respectively. The analyzed zone was restricted to a diameter of $33 \mu \mathrm{m}$ to limit the edge effects on the SIMS crater. The depth of the resulting 150x150 $\mu \mathrm{m}^{2}$ SIMS crater was measured using a Dektak8 sept-meter instrument. The secondary ions of masses 12 (carbon), 26 (carbon+nitrogen) and 31 (phosphorus) were detected. The analysis have been done at low mass resolution, $\mathrm{M} / \Delta \mathrm{M}<$ 400. The quantification of the phosphorus concentration was made thanks to an ion-implantation standard with a known dose of phosphorus. The detection limit for phosphorus was $\sim 5 \times 10^{15} \mathrm{at} / \mathrm{cm}^{3}$. This method typically gives the phosphorus concentration with a $10 \%$ relative uncertainty.

The resistance, $\mathrm{R}$, of the (111) overdoped epilayers was measured using a JANDEL 4-point probe with a low noise Keithley 6221 current generator and a Keithley 2000 multimeter with a $10 \mathrm{G} \Omega$ input for voltage measurements. The compliance voltage of the current source was set to $105 \mathrm{~V}$. The current range was set between -20 and $20 \mu \mathrm{A}$. Each sample being square, the resistance measurement was performed on each of its two diagonals, then repeated again with an opposite current, for a total of 4 to 12 measurements per sample, to verify the absence of asymmetry during the measurement. The conductivity $\sigma$ of the samples was deduced from the formula $\sigma=1 /$ (f.d.R), where $\mathrm{d}$ is the thickness of the epilayer and $\mathrm{f}=3.74$ is a correction factor relative to the probe spacing $(0.5 \mathrm{~mm})$ and the sample diameter. The relative uncertainty on $\sigma$ was estimated to approximately $25 \%$.

\section{Results and discussion}

3.1 Microstructuration of (100) diamond The natural alignment along the [110] and [-110] crystallographic directions of the nickel-etched microstructures shown in Fig. 2 can also be observed in the works of Smirnov et al. [8] and Mehedi et al. [9]. The borders of the microstructures are found to be parallel to the [110] and [-110] directions (Fig.2.b). The mean diagonal size of the microstructures was determined from the measurement of 112 microstructures, yielding a value of $491 \pm 219 \mathrm{~nm}$. By using a rectangular paving over the planar microstructure-covered area, a binary image was extracted from which the microstructure cover rate was calculated to be $25 \% \pm 10 \%$.
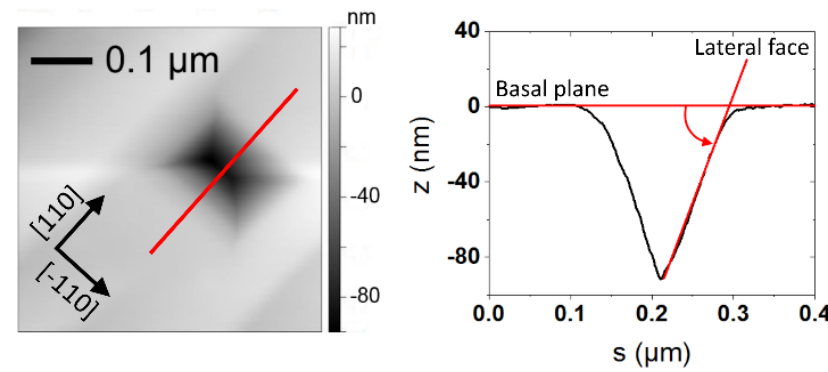

Figure 3 AFM $0.5 \times 0.5 \mu \mathrm{m}^{2}$ sample image of an inversed pyramidal-shaped microstructure at the surface of $\mathrm{Ni}-2$ after chemical removal of the Ni particles. The red line represents a cross-sectional view in the [110] direction, along which the depth $\mathrm{z}$ is plotted to measure the angle between the (100) basal plane and the face of the inversed-pyramid.

Measurements of the angle between the (100) surface and the lateral faces of the microstructures were performed by AFM on 12 microstructures, each in the [110] and [-110] 
directions, for a total of 24 measurements. Fig. 3 shows a $0.5 \times 0.5 \mu \mathrm{m}^{2}$ example image of one such microstructure. Mean angle values of $50^{\circ}$ and $49.5^{\circ}$ were found respectively to the [110] and the [-110] directions with standard deviation of $6^{\circ}$ and $5^{\circ}$. These values are very close to each other, indicating that the etching was indeed anisotropic and homogenous over the surface sample. They are consistent with the closest crystallographic angle of $54.74^{\circ}$ between the (111) and (100) planes. These results indicate that the faces of etched pyramidal holes are (111)-oriented.

3.2 Conductivity of (111) epilayers Fig. 4 shows the phosphorus content in sample D215 with the layer/substrate interface located at $95 \mathrm{~nm}$ from the surface. The phosphorus concentration and the layer thickness measured by SIMS are summarized in Table 1 for each (111) epilayer, together with the corresponding room temperature conductivity extracted from 4-point probe measurements.

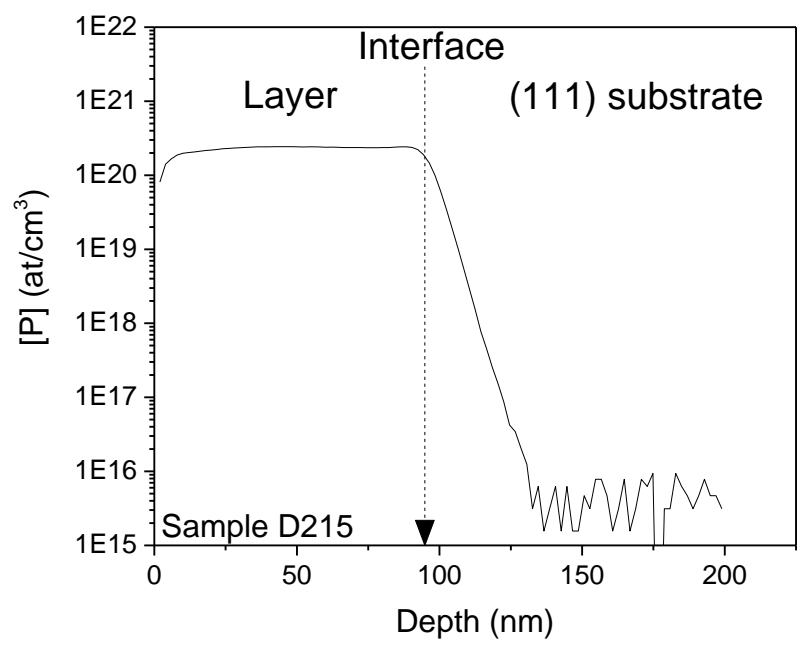

Figure 4 SIMS profile of the phosphorus content for sample D215. The interface between the epilayer and the substrate is marked with a vertical dashed arrow located at $95 \mathrm{~nm}$.

The maximum room temperature conductivity is obtained for sample D215 with $\sigma=0.108 \Omega^{-1} \cdot \mathrm{cm}^{-1}$ for $[\mathrm{P}]=$ $2.3 \times 10^{20}$ at. $^{-3}$ and a $95 \mathrm{~nm}$ thickness. In Fig. 5 , the room temperature conductivity, $\sigma$, and the phosphorus concentration, [P], of samples D213 and D215 are compared to samples D51, D52, D94, D95 and D97, as well as other works published in the literature $[10,12,13,14]$. These results show that the electrical conductivity of (111) phosphorusdoped diamond is maximum when the layer is thin and grown at high temperature. It then exceeds previously published results by almost one decade.
Table 1 Growth conditions and characteristics of the (111) epilayers. All samples were grown with a total gas flow of $1000 \mathrm{sccm}$, a pressure of $50 \mathrm{mbar}$ and with $\left[\mathrm{CH}_{4}\right] /\left[\mathrm{H}_{2}\right]=0.05 \%$. The dispersion of $[\mathrm{P}]$ is not yet clearly identify.

\begin{tabular}{cccccccc}
\hline Sample & $\begin{array}{c}\text { Miscut } \\
\text { angle }\end{array}$ & $\begin{array}{c}{[\mathrm{P}] /[\mathrm{C}]_{\text {gas }}} \\
(\%)\end{array}$ & $\begin{array}{c}\mathrm{T}_{\text {growth }} \\
\left({ }^{\circ} \mathrm{C}\right)\end{array}$ & $\begin{array}{c}\text { Growth } \\
\text { duration } \\
(\mathrm{h})\end{array}$ & $\begin{array}{c}\mathrm{d} \\
(\mathrm{nm})\end{array}$ & $\begin{array}{c}{[\mathrm{P}]} \\
\left(\mathrm{x} 10^{20}\right. \\
\left.\text { at.cm }{ }^{-3}\right)\end{array}$ & $\begin{array}{c}\sigma \text { at 300K } \\
\left(\Omega^{-1} . \mathrm{cm}^{-1}\right)\end{array}$ \\
\hline D51 & 2.9 & -- & 800 & 6 & 215 & 1.6 & 0.0046 \\
D52 & 2.7 & -- & 865 & 6 & 406 & 1.4 & 0.0029 \\
D94 & 3.2 & -- & 890 & 6 & 644 & 1.3 & 0.0060 \\
D95 & 3.3 & -- & 890 & 6 & 701 & 1.2 & 0.0047 \\
D97 & 3.2 & -- & 965 & 5 & 763 & 0.8 & 0.0052 \\
D213 & 1.9 & -- & 990 & 1 & 109 & 2.4 & 0.058 \\
D215 & 1.6 & -- & 1000 & 1 & 95 & 2.3 & 0.108 \\
D238 & 2.8 & 12 & 990 & 1 & 135 & 2.5 & 0.047
\end{tabular}

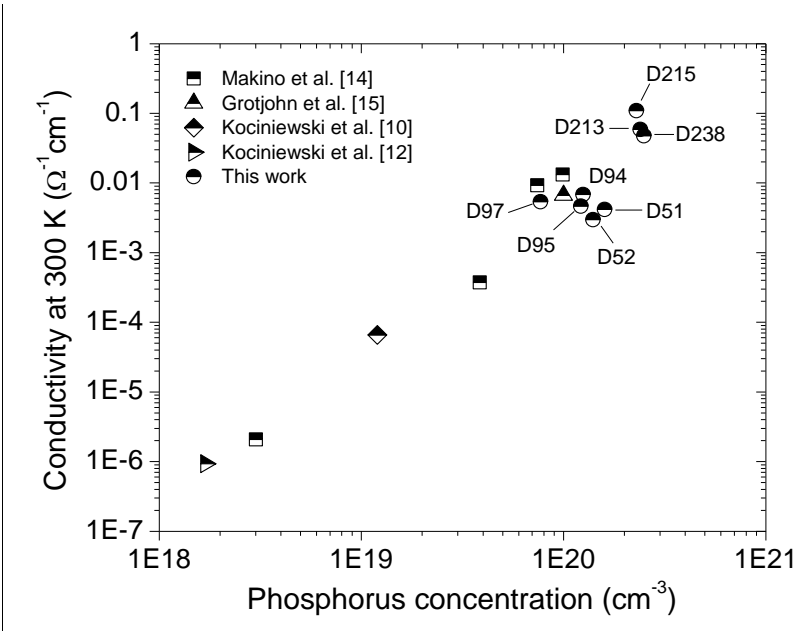

Figure 5 Room temperature conductivity, $\sigma$, with respect to the phosphorus concentration, [P], of the (111) epilayers presented in this work, and compared to previously reported works $[10,12,13$, 14].

The relative uncertainty on $\mathrm{T}_{\text {growth }}$ being $10 \%$, samples D213 and D215 are considered to be grown in the same conditions. They present similar results in term of phosphorus concentration and conductivity. We recently realized a film in the same growth conditions with intentional phosphorus doping: sample D238 with $[\mathrm{P}] /[\mathrm{C}]_{\text {gas }}=12 \%$. Such layer present identical phosphorus content and conductivity than samples D213 and D215: $[\mathrm{P}]=2.5 \times 10^{20}$ at $/ \mathrm{cm}^{3}$ and $\sigma=$ $0.047 \mathrm{~S} / \mathrm{cm}$. Note that no effect of substrate miscut is evidenced unlike in the work of Yamamoto et al. [15]. Our results show that high conductive and highly phosphorus doped (111) layers are controllable. 


\subsection{Selective growth in the inversed-pyramids} of the microstructured (100) substrates Sample Ni-2 was subjected to our set of growth parameters, that is to say the one of sample D215. The largest microstructures of SEM image in Fig. 6 show a distinct swelling attributed to the growth of diamond on top of the microstructures.

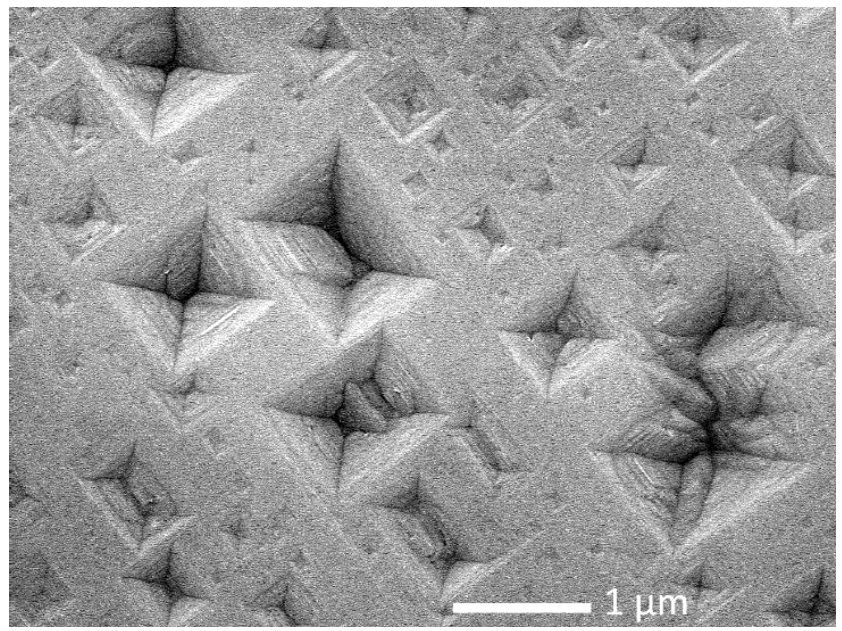

Figure 6 SEM image of the microstructured side of sample Ni-2 after being submitted to sample D215 growth conditions. The lateral faces of the inversed-pyramids present a distinct swelling.

The phosphorus SIMS distribution profile on the un-microstructured part of sample $\mathrm{Ni}-2$, after being submitted to the same growth conditions than sample D215, is shown in Fig. 6 (a). In the SIMS analysis conditions used here, the pre-equilibrium region corresponds to the first $25 \mathrm{~nm}$ of pulverized depth. In such region, no clear quantitative information can be extracted. As a result, after being submitted to the same the growth conditions that sample D215, the unmicrostructured region of sample Ni-2 present an epilayer thinner than $25 \mathrm{~nm}$. This indicates that, in our set of growth conditions, the growth rate is extremely slow on the (100) oriented surface.

After being submitted to the same growth conditions than sample D215, the microstructured region of sample Ni2 presents a phosphorus content with a maximum of $5.0 \times 10^{18} \mathrm{at} / \mathrm{cm}^{3}$ at $\sim 53 \mathrm{~nm}$, and then decreases until $750 \mathrm{~nm}$ where it reaches the detection limit (see Fig. 6). The presence of phosphorus in the microstructured region of sample $\mathrm{Ni}-2$ indicates that phosphorus epilayer was grown mainly inside the microstructures since nearly no layer could be detected on the (100) oriented surface. These results show the high selectivity of the phosphorus-doped diamond growth on the (111)-oriented facets of the etched microstructures compared to the (100) surface.
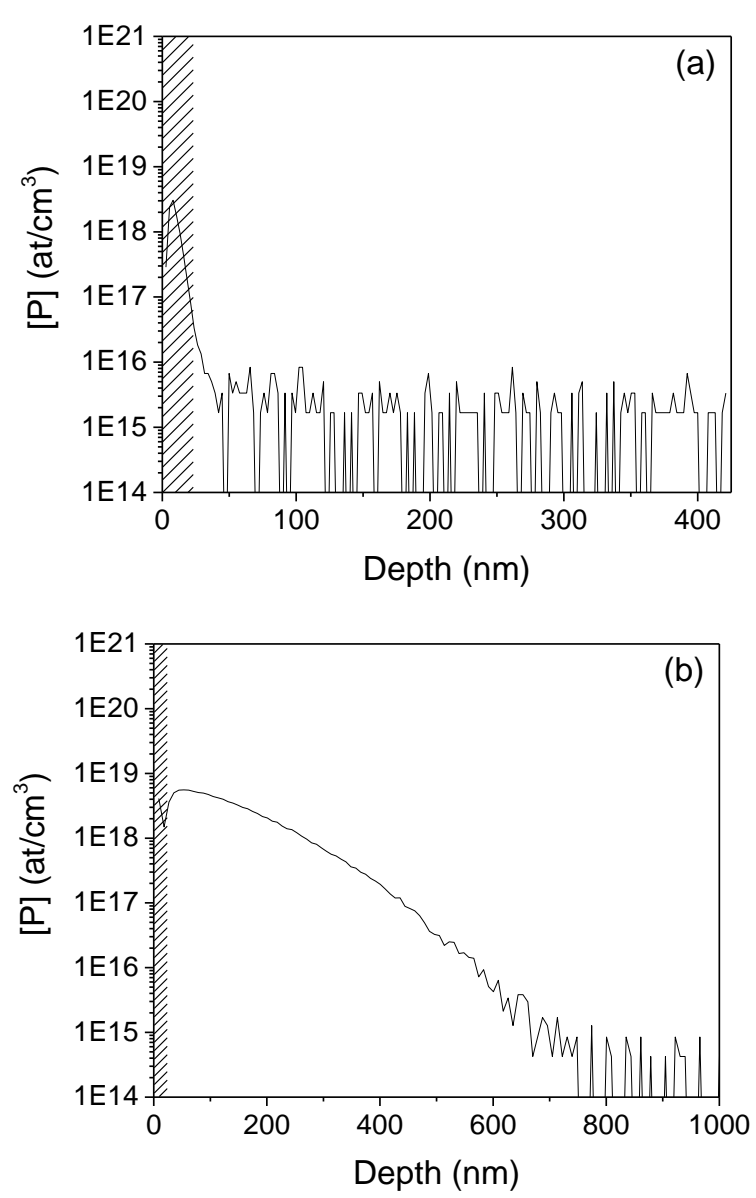

Figure 7 SIMS profiles of the phosphorus content, [P], of sample $\mathrm{Ni}-2$ after being submitted to the same growth conditions than sample D215 taken from: (a) a (100) surface without microstructuration and (b) a microstructured zone by $\mathrm{Ni}$-assisted etching. The dashed rectangles represent the pre-equilibrium region of the SIMS profile from which no clear quantitative information can be extracted (this region depends on the SIMS analysis conditions).

Phosphorus is incorporated in layers grown on the (111)-oriented lateral faces of the inverted pyramids. The absolute phosphorus concentration inside the microstructure cannot be measured in a simple way with the sufficient spatial resolution. Nevertheless, with a microstructure cover rate of $25 \%$, the corresponding phosphorus concentration inside the pits is estimated to $2 \times 10^{19} \mathrm{at} / \mathrm{cm}^{3}$ (in Figure 7(b), $5 \times 10^{18} \mathrm{at} / \mathrm{cm}^{3}$ is an average value from (100) and (111) surfaces taken from the $50 \mu \mathrm{m}$ width SIMS analysis region). According to the work of Teraji et al. [6] this value appears sufficient to achieve (quasi-)ohmic contacts on n-type diamond. The phosphorus amount incorporated inside microstructures appears good enough for a process of contact fabrication. 

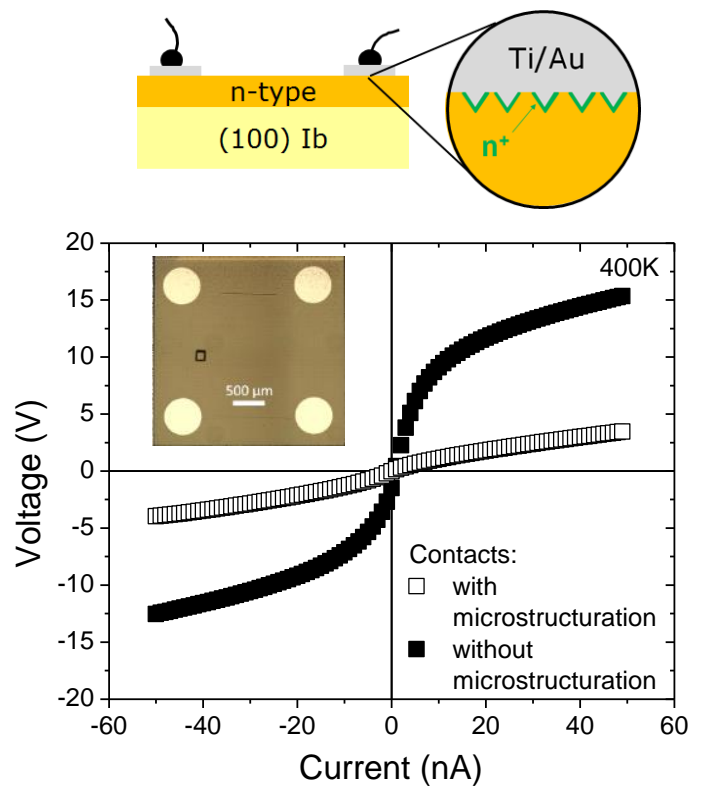

Figure 8 Current-voltage (I-V) characteristics between two neighbouring contact pads at $400 \mathrm{~K}$ without (black squares) and with (open squares) P-doped microstructures under Ti/Au contacts, for a phosphorus doped (100) diamond sample $\left([\mathrm{P}]=4.7 \times 1017 \mathrm{at} / \mathrm{cm}^{3}\right.$, thickness of $8 \mu \mathrm{m})$. The inset shows an optical microscopy image of the sample with contacts in the Van der Pauw configuration. The scheme above shows a transversal view of contacts with microstructuration (not at scale).

Figure 8 shows the current-voltage (I-V) characteristics at $400 \mathrm{~K}$ of a (100) phosphorus doped diamond homoepilayer $\left([\mathrm{P}]=4.7 \times 10^{17} \mathrm{at} / \mathrm{cm}^{3}\right.$ with a thickness of $\left.8 \mu \mathrm{m}\right)$ under the Van der Pauw configuration with Ti/Au metallic contacts. The black squares correspond to the measurement made without the microstructuration process and highly doped (111) selective growth investigated in this work. The open squares exhibits the data obtained while using our new process. A clear improvement of the I-V characteristics is observed, meaning that our new process for electrical contacts seems promising.

4 Conclusions A process of nickel-catalyzed plasmaetching was investigated for (100) oriented diamond, leading to the formation of inversed pyramidal shaped microstructures. The inner walls of these microstructures are oriented close to the (111) crystallographic planes of diamond. Growth experiments on (111)-oriented overdoped epilayers with our set of growth parameters lead to a maximum room temperature conductivity of $0.108 \Omega^{-1} \cdot \mathrm{cm}^{-1}$, exceeding previously published results by almost one decade.

When a microstructured (100) oriented substrate is submitted to this new set of parameters, phosphorus doped diamond is grown on the lateral faces of the inversed pyramids while nearly no diamond is grown outside of the microstructures. This indicates that such growth process is sufficiently selective for fabricating ohmic contacts on n-type diamond.
The selective growth of highly phosphorus doped diamond directly on the surface of Ni-etched microstructures naturally leads to an interesting prospect of achieving quasiohmic contacts by tunnel effect on n-type diamond. The proposed process is simplified compared to previous approaches, eliminating the alignment steps when using lithography or even the lithography process itself, as in this work. Complete electrical characteristics of such contacts are currently under investigation.

Acknowledgements The authors acknowledge the kind participation of Christèle Vilar for her help in SEM imagery.

\section{References}

[1] H. Okumura, Jpn. J. Appl. Physics 45, 7565 (2006).

[2] S. Koizumi, K. Watanabe, M. Hasegawa, and H. Kanda, Science 292, 1899 (2001).

[3] S. Koizumi, M. Kamo, Y. Sato, H. Ozaki, and T. Inuzuka, Appl. Phys. Lett. 71, 1065 (1997).

[4] T. Matsumoto, H. Kato, T. Makino, M. Ogura, D. Takeuchi, H. Okushi, and S. Yamasaki, Jpn. J. Appl. Phys. 53, 05 FP05 (2014).

[5] T. Teraji, S. Koizumi, and H. Kanda, Phys. Stat. Sol. A 181, 129 (2000)

[6] T. Teraji, M. Katagiri, S. Koizumi, T. Ito, and H. Kanda, Jpn. J. Appl. Physics 42, L882 (2003).

[7] H. Kato, T. Makino, M. Ogura, N. Tokuda, H. Okushi, and S. Yamasaki, Appl. Phys. Express 2, 55502 (2009).

[8] W. Smirnov, J.J. Hees, D. Brink, W. Müller-Sebert, A. Kriele, O. a. Williams, and C.E. Nebel, Appl. Phys. Lett. 97, 73117 (2010). [9] H. Mehedi, C. Hebert, S. Ruffinatto, D. Eon, F. Omnes, and E. Gheeraert, Nanotechnology 23, 455302 (2012).

[10] T. Kociniewski, J. Barjon, M.A. Pinault, F. Jomard, A. Lusson, D. Ballutaud, O. Gorochov, J.M. Laroche, E. Rzepka, J. Chevallier, and C. Saguy, Phys. Stat. Sol. A 203, 3136 (2006).

[11] M.A. Pinault-Thaury, I. Stenger, F. Jomard, J. Chevallier, J. Barjon, A. Traore, D. Eon, and J. Pernot, Phys. Stat. Sol. A 212, 2454 (2015).

[12] T.A. Grotjohn, D.T. Tran, M.K. Yaran, S.N. Demlow, and T. Schuelke, Diam. Relat. Mater. 44, 129 (2014).

[13] T. Kociniewski, M.A. Pinault, J. Barjon, F. Jomard, J. Chevallier, and C. Saguy, Diam. Relat. Mater. 16, 815 (2007).

[14] T. Makino, K. Oyama, H. Kato, D. Takeuchi, M. Ogura, H. Okushi, and S. Yamasaki, Jpn. J. Appl. Phys. 53, 05FA12 (2014). [15] T. Yamamoto, S.D. Janssens, R. Ohtani, D. Takeuchi and S. Koizumi, Appl. Phys. Lett. 109, 182102 (2016). 